\title{
Testing and performance of immobilized Fenton photoreactions via membranes, mats and modified copolymers
}

\author{
J. Fernandez, ${ }^{1}$ V. Nadtochenko, ${ }^{1}$ O. Enea, ${ }^{2}$ A. Bozzi, ${ }^{1}$ \\ T. Yuranova, ${ }^{1}$ and J. Kiwi ${ }^{1}$ \\ ${ }^{1}$ Laboratory of Photonics and Interfaces, Department of Chemistry, Swiss Federal Institute of Technology, \\ Lausanne1015, Switzerland \\ ${ }^{2}$ UMR 6503 CNRS, University of Poitiers, 86022, Poitiers, France.
}

\begin{abstract}
During the last 6 years our laboratory has developed Fenton immobilized catalysts for the partial or total destruction of toxic organic compounds and their mixtures. This paper reports on Fe-supported noncorrosive supported membranes and fabrics like: Nafion, Nafion-glass mats and polyethylene block copolymers. These novel supported catalysts have shown acceptable kinetic rates, resistance to the leaching of $\mathrm{Fe}^{3+}$ into the solution and no corrosion to the highly oxidative radicals generated in the solution during Fenton immobilized photo-assisted catalysis. Nafion-Fe membranes degrade Orange II under visible light only up to $\mathrm{pH}$ 4.8. In the case of nafion glass mats supported $\mathrm{Fe}^{3+}$-ions, the initial $\mathrm{pH}$ could be raised up to 8 or above. The $\mathrm{pH}$ decreased to about 4 during the photodegradation of Orange II due to the formation of intermediate carboxylic acids but the costly initial acidification process necessary in the case of homogeneous Fenton processes is avoided. Carboxylates and carboxylic acids were observed by IR spectroscopy on the surface of the supported catalysts towards the end of the photodegradation process as well as carboxylic acids detected by HPLC. The IR bands are found at 1523 and $1557 \mathrm{~cm}^{-1}$ in the case of the copolymer-Fe ${ }^{3+}$ corresponding to two types of iron-carboxylate species. The formation of carboxylates explains the drop of pH during the photodegradation to values between 3 and 4 corresponding to the $\mathrm{pK}_{\mathrm{a}}$ of the carboxylic functional group.
\end{abstract}

\section{INTRODUCTION}

During the last decade hydroxyl radical $\left(\bullet^{\circ} \mathrm{OH}\right)$ chemistry has attracted wide interest in oxidation technologies in wastewater treatment and the Fenton reagent [1] has been commonly used as source of $\bullet \mathrm{OH}$ radicals in acidic media

$$
\mathrm{Fe}^{2+}+\mathrm{H}_{2} \mathrm{O}_{2} \longrightarrow \mathrm{Fe}^{3+}+\mathrm{OH}^{-}+\cdot \mathrm{OH}
$$

Recently [2] it has been shown that UV-Vis light accelerates reaction (1) improving the degradation rates of many organic compounds e.g.; the non-biodegradable azo-dye Orange II taken a model compound in this study [3, 4]. Iron salts as shown in eq. (1) have been known to be the most common catalysts for $\mathrm{H}_{2} \mathrm{O}_{2}$ decomposition in acidic media. They have been used under light irradiation for this purpose in concentrations of $20-50 \mathrm{mg}$ Fe-ion/L and in dark reactions at much higher concentrations. Only in this way a suitable $\mathrm{H}_{2} \mathrm{O}_{2}$ decomposition kinetics with meaningful yields of $\cdot \mathrm{OH}$-radicals as shown in eq. (1) were attained in photo-assisted Fenton reactions [5, 6]. Fe-sludge disposal and/or regeneration after the Fenton reactions is a serious problem during pollutant degradation in homogeneous media. The removal of iron-ions is a relatively simple operation commonly carried out by precipitation and re-dissolution of the Fe-ions after the treatment of large volumes but it implies the use of large amounts of chemicals and manpower. This costly regeneration step has therefore to be avoided. After the Fenton treatment of waste-waters the remaining Fe-ions are found at concentrations far above the levels allowed in waste waters by the EEC regulations of $2 \mathrm{ppm}$ [1]. In order to overcome such drawbacks we undertook the present study. In this study we sought to explore the possibility of highly dispersed Fe-ions supported on to dissolved Nafion membranes having similar effect as Fe-ions on the decomposition of $\mathrm{H}_{2} \mathrm{O}_{2}$ in homogeneous solution. The immobilization the Fe-ions on a membrane allows the catalysis of the disappearance of Orange II under light in a novel as compared to homogeneous solutions avoiding the drawbacks of the disposal of the iron-ions at the end of the treatment. This new approach will be applied to a non-biodegradable azo-dye (Orange II) found in the effluents of the textile industry $[8,9]$ as part of the studies conducted by our group in the emerging field of Advanced Oxidation Technologies (AOT's).

Membrane related research has attracted much attention in recent years as a structured medium for photochemical reactions. Nafion perfluorinated membranes (Dupont) have been used during the last decade in a variety of catalytical/electrocatalytical integrated chemical reactions [10]. Polymer membranes have also been used for charge transfer in inorganic and biological systems [11]. Very few studies of chemical 
transformations on photo-activation loaded membranes containing $\mathrm{CdS}$ or $\mathrm{TiO}_{2}$ [12-15] reactions have been reported until now. Reactions on Fe-loaded polymer membrane systems have recently reported [16]. In the present study the non-biodegradable azo-dye Orange II has been chosen as a probe and its degradation in aqueous solution has been investigated. Azo-dyes account for more than $22 \%$ of the world dye production and are commonly found in effluents of the textile industry [5-7]. The hydroxylation/oxidation of Orange II $[3,4]$ provides a suitable test for the oxidative degradation of this material under conditions relevant and technical systems. The pretreatment proposed in on the supported materials described in this study has shown to be effective for subsequent biological treatment-a low cost process-to complete the abatement of pollutants.

\section{RESULTS AND DISCUSSIONS}

2.1. Nafion- $\mathrm{Fe}^{3+}$ membranes as photocatalysts. Figure 1 shows the disappearance of Orange II ( $\mathrm{pH} 2.8$ ) under light irradiation on a Fe-loaded Nafion membrane

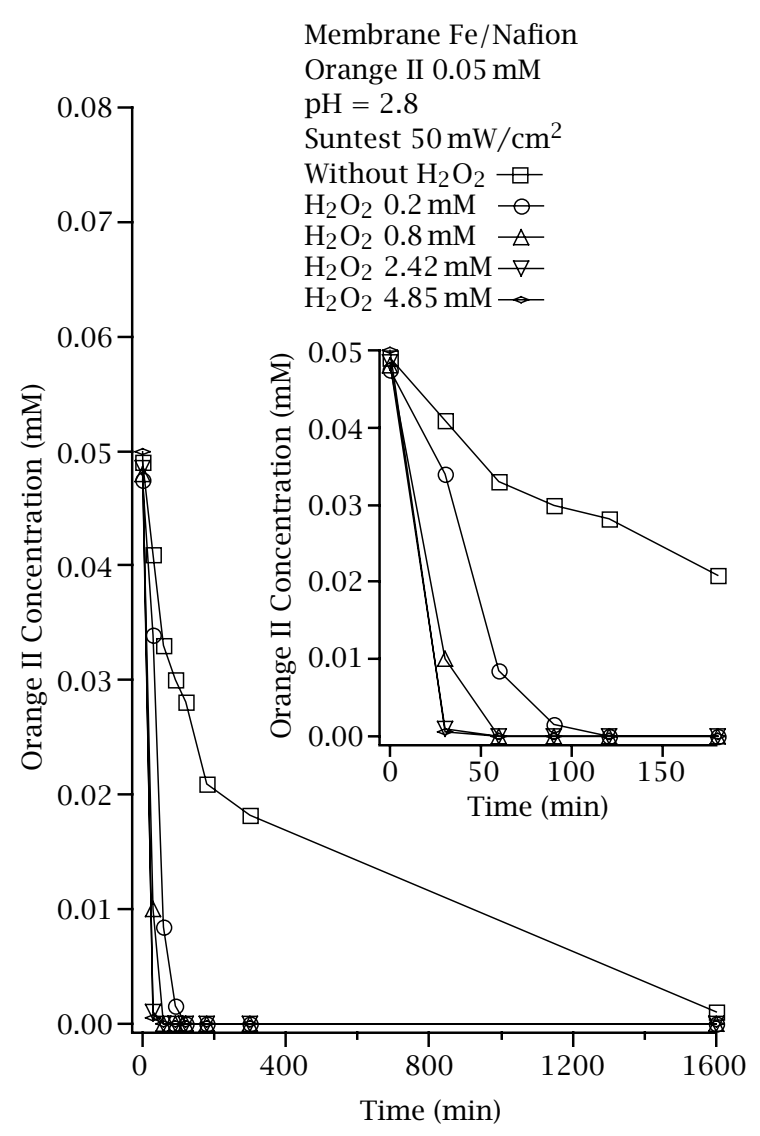

Figure 1. Disappearance of Orange II on Nafion/ $/ \mathrm{Fe}^{3+}$ under simulated solar light followed by high liquid pressure chromatography as a function of time. Other experimental conditions are indicated in the Figure caption. by a (Sun test lamp) as a function of time for different concentrations of $\mathrm{H}_{2} \mathrm{O}_{2}$ in the solution. With increasing concentration of $\mathrm{H}_{2} \mathrm{O}_{2}$ the Orange II degradation kinetics was accelerated. Above $\mathrm{H}_{2} \mathrm{O}_{2}$ concentrations greater than $0.8 \mathrm{mM}$, no further acceleration was observed occurring during Orange II degradation. This is due to the known scavenging effect when using higher $\mathrm{H}_{2} \mathrm{O}_{2}$ concentration on the further generation of hydroxyl radicals in solution [8]. The inset in Figure 1 shows a more detailed kinetics at times $<200 \mathrm{~min}$. The concomitant total organic carbon (TOC) decrease was observed to be modest going from 16 to $11 \mathrm{ppm} \mathrm{C}$ after $120 \mathrm{~min}$. Within this time the azo-dye is observed to completely disappear from the solution. Concomitant $\mathrm{CO}_{2}$ evolution was checked by gas chromatographic technique (GC) confirming that mineralization of the dye proceeds with a much slower kinetics than the Orange II disappearance. This reveals the formation of longer lived intermediates in solution. The decoloration shown in Figure 2 reflects the azo-bond breakage in Orange II [10]. During dye abatement where $\mathrm{H}_{2} \mathrm{O}_{2}(0.8 \mathrm{mM})$ is added, the solution $\mathrm{pH}$ was seen to increase from 2.8 to $\sim 3.2$.

Membrane Fe/Nafion Orange II $0.05 \mathrm{mM}$ Suntest $50 \mathrm{~mW} / \mathrm{cm}^{2}$ $\mathrm{pH}=2.8$

$\mathrm{H}_{2} \mathrm{O}_{2} 4.85 \mathrm{mM}$
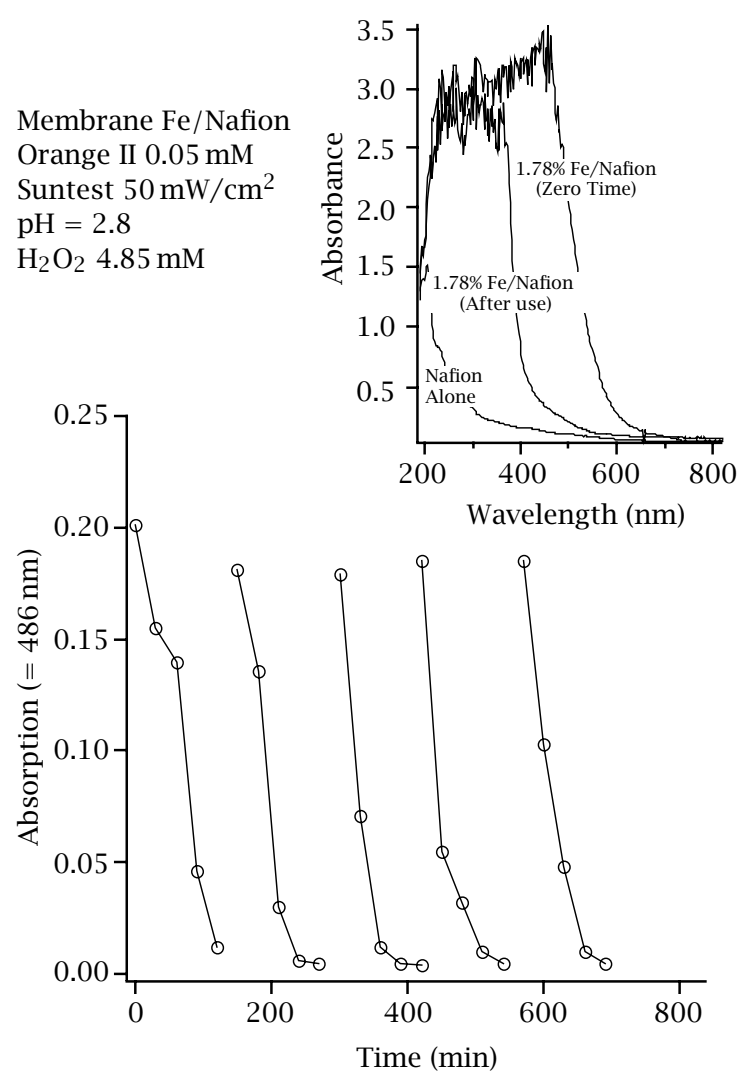

Figure 2. Nafion/ $/ \mathrm{Fe}^{3+}$ membrane catalytic degradation of Orange II as a function of time followed by visible spectral observations at the Orange II peak $\lambda=486 \mathrm{~nm}$ up to the 5th cycle. The inset shows the the spectral change of the Nafion within 500 hours irradiation due to the formation of $\mathrm{Fe}^{2+}$ from the initial $\mathrm{Fe}^{3+}$. 
This corresponds to about a fourfold increase in the $\mathrm{OH}^{-}$concentration in the solution and suggests that reaction (2)

$$
\begin{aligned}
\text { Nafion } / \mathrm{Fe}(\mathrm{II})+\mathrm{H}_{2} \mathrm{O}_{2} \\
\\
\longrightarrow \text { Nafion } / \mathrm{Fe}(\mathrm{III})+{ }^{\cdot} \mathrm{OH}+\mathrm{OH}^{-}
\end{aligned}
$$

as the main pathway for Orange II degradation and not reaction (3)

$$
\begin{aligned}
& \text { Nafion/Fe(III) }+\mathrm{H}_{2} \mathrm{O}_{2} \\
& \quad \longrightarrow \text { Nafion/Fe(II) }+\mathrm{HO}_{2} \cdot+\mathrm{H}^{+} .
\end{aligned}
$$

Three experimental observations substantiate further the mechanism suggested in eq. (1): a) methanol $(0.26 \mathrm{M})$ precluded the abatement of the azo-dye observed in Figure 1 due to its $\cdot \mathrm{OH}$ radical scavenging properties, b) spectrophotometric results showed that the initial Nafion/Fe(III) membrane decolored substantially during the photolysis due to the build-up of Nafion/Fe(II) absorbing at much lower $\lambda$ s. Since the iron has been exchanged at room temperature in aqueous solution the exchanged-hydrated Nafion/Fe(III) would involve the presence in the Nafion of the Fe-species: $\mathrm{Fe}(\mathrm{OH})^{2+} \varepsilon_{366 \mathrm{~nm}}=275 \mathrm{M}^{-1} \mathrm{~cm}^{-1}$ and $\mathrm{Fe}_{2}(\mathrm{OH})_{2}{ }^{4+} \varepsilon_{366 \mathrm{~nm}}=1000 \mathrm{M}^{-1} \mathrm{~cm}^{-1}$ [18]. During the dye decoloration (shown in Figure 2) the orange-brown color of Nafion/Fe(III) gradually disappears due to the formation of the much lower absorption from the charge transfer band of $\mathrm{Fe}\left(\mathrm{H}_{2} \mathrm{O}\right)_{6}{ }^{2+}$ observed below $\lambda=265 \mathrm{~nm}$ with $\varepsilon_{254} \mathrm{~nm}=20 \mathrm{M}^{-1} \mathrm{~cm}^{-1}$ [19] and finally c) if the superoxyde radical $\mathrm{HO}_{2}{ }^{\bullet}\left(\mathrm{pK}_{\mathrm{a}}=4.8\right)$ would be photo-produced in eq. (2) the latter radical has a considerably lower one electron standard reduction potential of $\mathrm{E}^{\circ}=0.75 \mathrm{~V}$ vs NHE $\left(\mathrm{HO}_{2} / \mathrm{O}_{2}{ }^{--}\right)$than the ${ }^{\bullet} \mathrm{OH}$ radical with $\mathrm{E}^{\circ}=1.90 \mathrm{~V} v s$ NHE [20] $\left({ }^{\circ} \mathrm{OH} / \mathrm{OH}^{-}\right)$in eq. (1). The fast oxidation of the Orange II observed in Figure 1 cannot possibly be explained in terms of this kinetically slower and less energetically $\mathrm{HO}_{2}$ ' radical (eq. (2)).

Figure 2 shows the repetitive nature of the Orange II photodegradation in the presence of of Nafion/Feloaded membrane and $\mathrm{H}_{2} \mathrm{O}_{2}$. After about 25 cycles, the membrane was regenerated by immersion in a solution $\mathrm{NaOH} 1 \mathrm{M}$. The timing of this regeneration was determined by two factors: a) During use, the initial orangebrown coloration with an absorption (up to $\lambda=600 \mathrm{~nm}$ ) slowly changed to gray-yellowish with a spectral absorption reaching only the upper limit of $\lambda \sim 410 \mathrm{~nm}$. This indicated that during the photolysis the Fe(III) content in the Nafion membrane decreased leading to the formation of the colorless Fe(II)-ion since the total iron content of the membrane was seen to remain constant (see text below). The Nafion without any Feloading absorbed only below $300 \mathrm{~nm}$ and $\mathrm{b}$ ) during the degradation cycles the membrane become kinetically faster with time. That is the degradation cycles in Figure 2 occur within less time and Orange II degradation in times shorter than $\sim 40 \%$ were observed compared to first degradation run. Nafion/Fe(II) highly stable species are probably responsible for the observed process acceleration as the reaction progresses in time.

The assessment of the oxidation state of the iron during the reaction was carried out by photoelectron spectroscopy (XPS) in a Leybold-Heraeus instrument. The quantitative evaluation of the Fe(III) and Fe(II) species before and after 120 min light reaction revealed $78 \% \mathrm{Fe}(\mathrm{III})$ at $710.0 \mathrm{eV}$ (B.E.) and $22 \%$ $\mathrm{Fe}(\mathrm{III}) / \mathrm{Fe}$ (II) species at $713.8 \mathrm{eV}$ (B.E.) at time zero. The former species appeared mainly as $\mathrm{Fe}_{2} \mathrm{O}_{3}$ while the latter species consisted mainly of the composite $\mathrm{Fe}_{3} \mathrm{O}_{4}$ oxide showing the peaks for the constituent oxides. After reaction, the Nafion membrane showed $16 \%$ of $\mathrm{Fe}$ (III) and $84 \%$ of the $\mathrm{Fe}(\mathrm{III}) / \mathrm{Fe}$ (II) oxidation states. The corrections for electrostatic charging of the particles during the measurements was carried out by the polynomial fit of the data with a Shirley-type background subtraction. The XPS experimental result further confirms the spectral change in the Fe-Nafion membrane observed during the photocatalysis. The size of the Feclusters on the Nafion was determined by transmission electron microscopy (TEM) to be $37 \pm 4 \AA$ by way of a Philips $20 \mathrm{M}$ instrument. The particles were seen to be uniformly deposited on the Nafion and the size distribution was narrowly centered around the median value

The inset in Figure 2 shows the change in absorption of the Nafion membranes with time. After 500 hours irradiation a substantial change in absorption of the Nafion/Fe(III) with respect to the absorption observed at time zero. A decrease in the absorption of Nafion/Fe(III) is observed along the concomitant growth of the lower absorbing Nafion/Fe(II). This change in optical density is consistent with the molar absorption coefficients and the XPS evidence presented above in this study. The optical absorption of Nafion membranes is shown in the left-hand side of the inset. The formation of Q-sized Fe(III)/Fe(II) clusters in the Nafion upon irradiation has been confirmed by X-ray diffraction (XRD). The exchange procedure used to incorporate Fe-ions in the membrane is therefore also a method to produce nano-sized particles of iron oxides embedded in the polymer structure.

Based on the experimental results outlined above in the text to (Figures 1 and 2) a simplified scheme of reaction is presented in Scheme 1. Scheme 1 shows the photocatalytic degradation of Orange II in acidic solutions due to the photoproduction of oxidative radicals in solution and the build up of Nafion(Fe(III)/Fe(II))species during the degradation process.

More recently [21], Orange II abatement in a membrane based reactor has been reported. Nafion/ $/ \mathrm{Fe}^{3+}$ (1.78\%) membrane was used under Blue Actinic light (366 $\mathrm{nm}$ and $36 \mathrm{~W}$ ) in a 1.20 long concentric immersion reactor. The degradation up to bio-compatibility of the azo-dye Orange II proceeds at acceptable kinetic 


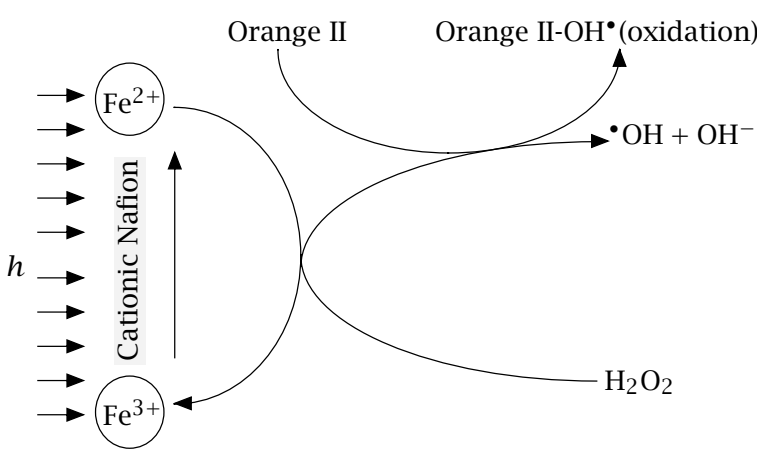

Scheme 1 .

rates but only up to $\mathrm{pH} 4.7$ as reported in ref. [21]. The membrane was left to freely float between the light and the walls of the reactor system shown in Figure 3. The intermediates of the degradation were observed to be bio-compatible after the initial scission of the $-\mathrm{N}=\mathrm{N}-$ bond of Orange II.

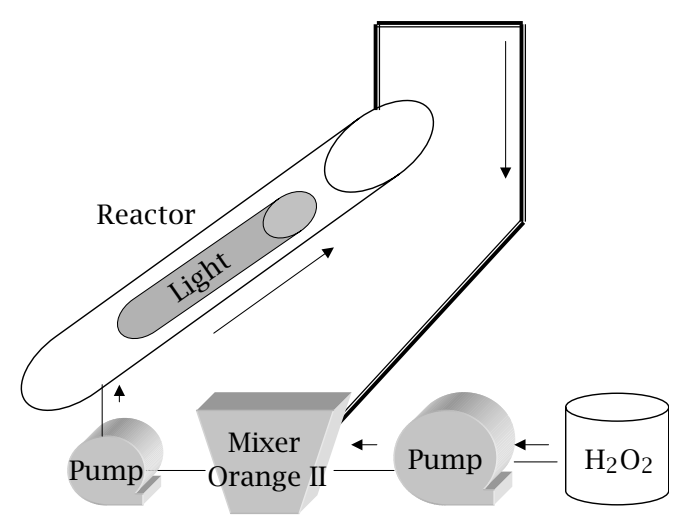

Figure 3. Schematic of the photoreactor used in the degradation of Orange II.

\subsection{Nafion/ $\mathrm{Fe}^{3+}$ glass mats as heterogeneous} photocatalyst for Orange II abatement. The azodye Orange II has been taken as a model azo-dye to monitor the decoloration and degradation in photoFenton reactions on Nafion/ $/ \mathrm{Fe}^{3+}$ membranes [22]. These processes were possible only up to $\mathrm{pH} 4.7$ since at this pH apparently active components of the Fecluster on the Nafion membrane deactivate due to precipitation [22].

More recently [23] Fe-ions were exchanged on Nafion droplets that were later attached to glass-mats. The Nafion oligomer containing the Fe-ions achieved a suitable dispersion on the glass-mats and the degradation of the model azo-dye was possible. Harmer et al. [24], has shown that acid groups of the Nafion are more accessible in Nafion-glass composites. The accessibility of these sulfonic groups leads to an improved ion-exchange capacity at the interface between Nafion and the glass-mat. Therefore, different

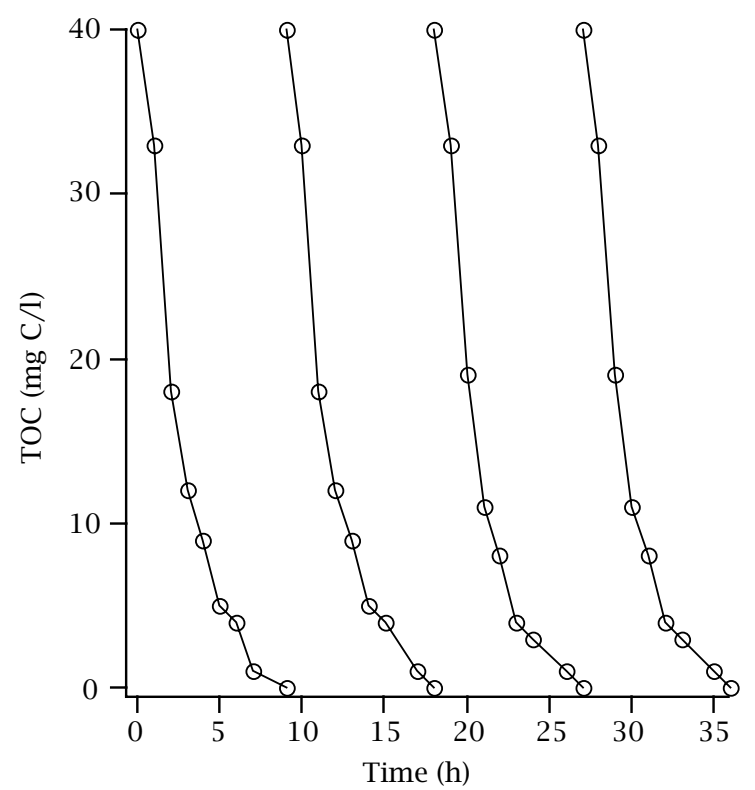

Figure 4. Repetitive photocatalytic mineralization of Orange II $(0.20 \mathrm{mM})$ on $\mathrm{Fe}^{3+} /$ Nafion/glass fibers under Suntest light in the presence of $\mathrm{H}_{2} \mathrm{O}_{2}(10 \mathrm{mM})$.

Fe-clusters may be present on the Nafion-glass composites compared to Nafion/ $/ \mathrm{Fe}^{3+}$ membranes. The decoloration/degradation of Orange II proceeded at a rate close to the one observed on Nafion/ $/ \mathrm{Fe}^{3+}$ [22] and the catalyst could be recycled without loosing his efficiency many times showing the stable nature of the process under study as shown in Figure 4.

Figure 4 presents the catalytic nature of the decoloration of Orange II under Suntest irradiation on $\mathrm{Fe}^{3+}$ /Nafion/glass fibers in the presence of $\mathrm{H}_{2} \mathrm{O}_{2}$. At the end of each degradation cycle, suitable amounts of Orange II and $\mathrm{H}_{2} \mathrm{O}_{2}$ were added to the original solution as selected for the photocatalysis. The results in Figure 4 confirm the photocatalytic nature of Orange II degradation. No measurable amounts of $\mathrm{Fe}^{3+}$-ions were found applying the thiocyanate test. The absence $\mathrm{Fe}^{2+}$-ions was analyzed by complexation with phenanthroline.

The mechanism of Orange II photocatalytic degradation on Nafion/ $/ \mathrm{Fe}^{3+}$ /glass mats under visible light irradiation is shown in Scheme 2.

Repetitive mineralization of Orange II under Suntest irradiation on $\mathrm{Fe}^{3+}$ /Nafion was observed to proceed up to $\mathrm{pH} 4.7$ [22]. But when $\mathrm{Fe}^{3+} /$ Nafion/glass mats were taken as photocatalysts the decoloration of Orange II solutions was observed to occur in the $\mathrm{pH}$ range 2.8-9.0 as shown in Figure 5. Since with $\mathrm{Fe}^{3+}$ /Nafion/glass mats degradation of Orange II is possible up to pH 8 as shown in Figure 5, we should save the cost of acidification of effluents with $\mathrm{pH}$ 6-9 when applying photo-Fenton treatment and only would have to add base at the end of the pre-treatment to attain again $\mathrm{pH} 6$ to couple the Fenton pretreatment with 


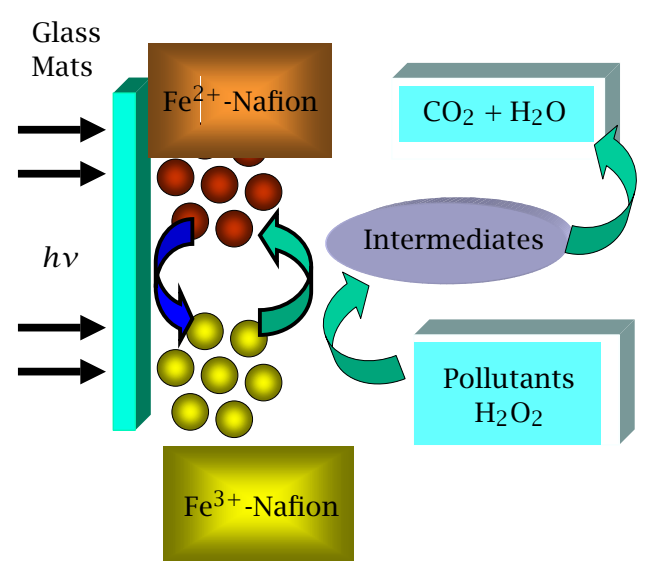

Scheme 2.

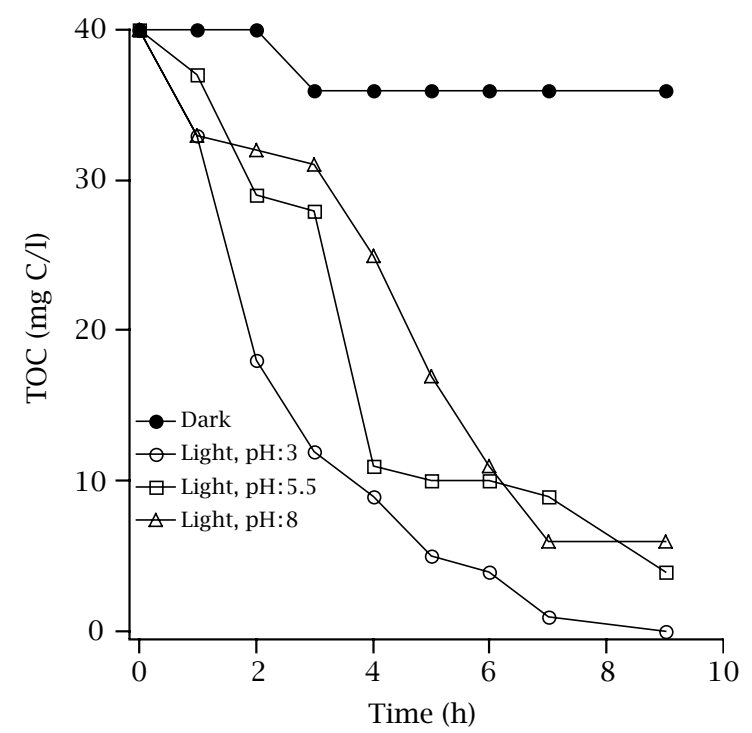

Figure 5. Mineralization of Orange II $(0.20 \mathrm{mM})$ in the dark (full points) and under Suntest light irradiation (open points) on $\mathrm{Fe}^{3+} /$ Nafion/glass fibers at three different initial $\mathrm{pH}$ values in the presence of $\mathrm{H}_{2} \mathrm{O}_{2}(10 \mathrm{mM})$.

biological secondary processing. Acidification is costly and exceeds the cost of the oxidant and the energy used during the Fenton treatment of large volumes of waste waters.

Figure 6 shows decrease in the total organic carbon content (TOC) for Orange II solutions having different dye concentrations. The mineralization in the dark is seen to be $<10 \%$ for solutions Orange II $(0.20 \mathrm{mM})$ due to the decomposition of $\mathrm{H}_{2} \mathrm{O}_{2}$ by the $\mathrm{Fe}^{3+} / \mathrm{Nafion} /$ glass mats. Addition of $\mathrm{H}_{2} \mathrm{O}_{2}$ to Orange II $(0.20 \mathrm{mM})$ did not lead to any observable mineralization in the absence of $\mathrm{Fe}^{3+} /$ Nafion/glass mats. The mineralization of Orange II is seen to proceed under Suntest light irradiation for different concentrations of Orange II in Figure 6. The steeper decline in the TOC observed at higher

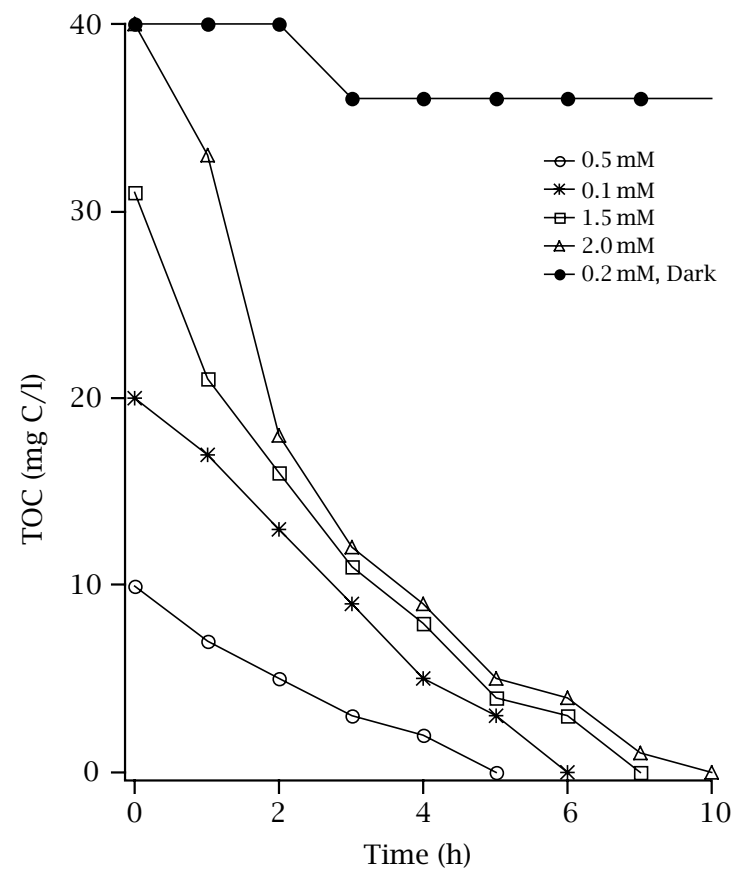

Figure 6. Mineralization of Orange II solutions of different concentrations on $\mathrm{Fe}^{3+} /$ Nafion/glass fibers in the dark and under Suntest light irradiation $\left(80 \mathrm{~mW} / \mathrm{cm}^{2}\right)$ in the presence of $\mathrm{H}_{2} \mathrm{O}_{2}(10 \mathrm{mM})$ at $\mathrm{pH}$ 3. Open points denote runs under light and the full points refer to the run in the dark.

Orange II concentrations is due to the more favorable mass transfer taking place between the solution Orange II and the $\mathrm{Fe}^{3+} /$ Nafion/glass fibers during reaction. The mass transfer between the solution and the $\mathrm{Fe}^{3+} /$ Nafion/glass fibers is driven by the difference in Orange II concentration existing between the bulk of the solution and the glass mat interface. The diffusion length $(x)$ of the oxidative-radical away from the glass mat can be estimated from the Smoluchowski diffusion relation

$$
x^{2} \cdot \mathrm{D} T
$$

The reaction rate between the $\mathrm{OH}^{\circ}$ radical and Orange II has been recently reported to be close to $10^{9} \mathrm{M}^{-1} \mathrm{~s}^{-1}$ [25]. At a concentration of Orange II $(0.20 \mathrm{mM})$, the lifetime of the encounter pair is $\sim 10^{-6} \mathrm{~s}$. With $\mathrm{D} \sim 5 \times 10^{-6} \mathrm{~cm}^{2} / \mathrm{s}$, a value for the diffusion length $(x)$ of $\sim 50 \mathrm{~nm}$ eq. (4) is found for the $\mathrm{OH}^{\circ}$ radical. In the case of the $\mathrm{HO}_{2}{ }^{\circ}$ radical, the value of the reaction rate of $\mathrm{HO}_{2}{ }^{\circ}$ with Orange II is found to be $\sim 10^{6} \mathrm{M}^{-1} \mathrm{~s}^{-1}$. From this a diffusion length of $\sim 310 \mathrm{~nm}$ can be estimated for the $\mathrm{HO}_{2}{ }^{\circ}$ radical away from the $\mathrm{Fe}^{3+} /$ Nafion/glass.

A $\mathrm{pH}$ drop during the degradation of Orange II was observed when starting at $\mathrm{pH}$ values 8.0 on $\mathrm{Fe}^{3+} /$ Nafion/glass mats due to two factors: a) the mineralization of Orange II produces $\mathrm{HSO}_{4}{ }^{-}$and predominantly $\mathrm{NH}_{4}{ }^{+}$[22] acidifying the initial dye solution and b) Fe-carboxylates and carboxylic acids are also produced in solution during the degradation of 


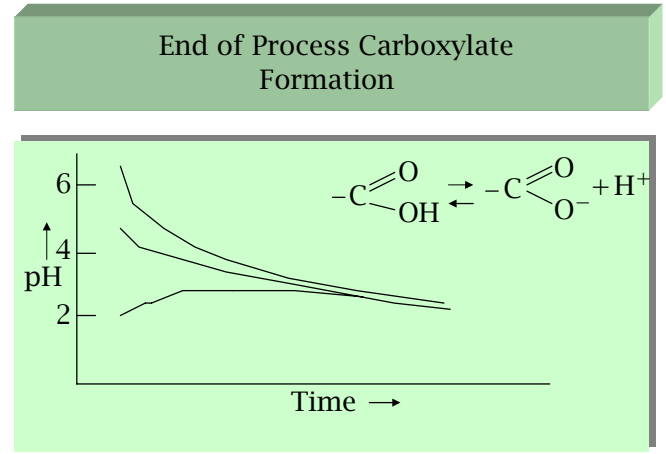

Figure 7. Variation of $\mathrm{pH}$ with time on Nafion/ $/ \mathrm{Fe}^{3+} /$ glass mats for Orange II and other organic compounds under light irradiation.

Orange II. Oxalic, formic and acetic and smaller concentrations of other acids have been reported during the mineralization of Orange II [26]. The $\mathrm{pH}$ of the solution at the end of the degradation was observed to be in the region to the $\mathrm{pK}_{\mathrm{a}}$ of the short carboxylic acids already mentioned. More interesting the final $\mathrm{pH}$ of the solution after Orange II degradation on $\mathrm{Fe}^{3+} / \mathrm{Nafion} /$ glass mats attains the value corresponding to the $\mathrm{pK}_{\mathrm{a}}$ of the carboxylate group independently of the initial $\mathrm{pH}$ of the Orange II solution. This is shown in Figure 7. This is interesting since Fenton reagent $\mathrm{Fe}^{3+} / \mathrm{H}_{2} \mathrm{O}_{2}$ does not produce by itself a decrease of the $\mathrm{pH}$ in the aqueous solution when generating the $\mathrm{OH}^{\circ}$ and $\mathrm{HO}_{2}{ }^{\circ}$ radicals leading to the destruction of the organic compound as shown in Scheme 3. Therefore, the degradation of Orange II involves the formation of Fe-organic complexes is noted as

$$
[\mathrm{RCOO}-\mathrm{Fe}]^{2+}+h v \rightarrow\left[\mathrm{R}^{\bullet}\right]+\mathrm{CO}_{2}+\mathrm{Fe}^{2+},
$$

where the LMCT complex in eq. (5) is the precursor step leading to the abatement of Orange II. Equation (5) proceeds concomitantly to the radical reaction contributing to the organic compound degradation

$$
\mathrm{RH}+\mathrm{HO}^{\circ}\left(\mathrm{HO}_{2}{ }^{\circ}\right) \longrightarrow\left[\mathrm{R}^{\bullet}\right]+\mathrm{RHOH} \text { or } \mathrm{H}_{2} \mathrm{O} \text {, }
$$

Fe-organic complexes or Fe-chelates intermediates like oxalates, maleates, pyruvates mentioned above in eq. (5) and decompose to $\mathrm{CO}_{2}$ with accelerated kinetics in Fenton photo-assisted reactions. But this decomposition would not occur due to the slow kinetics in dark reactions as observed during Fe-immobilized Fenton reactions mediating the photo-decomposition of Orange II [26] and coumaric acid [27]. Scheme 4 shows the competitive reactions taking place under light and in the dark. Nothing is practically known about the nature of the detailed nature of Fe-carboxylates in the presence of $\mathrm{H}_{2} \mathrm{O}_{2}$ although some studies have reported the existence of hydroperoxides [28] and unstable peroxyradicals [29] during Fenton traditional catalytic oxidation processes.
The $\mathrm{pH}$ of the Orange solution drops from 6 to $\sim 4$ during mineralization $\mathrm{Fe}^{3+}+\mathrm{H}_{2} \mathrm{O}_{2} \longrightarrow \mathrm{Fe}^{2+}+\mathrm{H}^{+}+\mathrm{HO}_{2} \cdot \mathrm{k}_{1}=0.02 \mathrm{M}^{-1} \mathrm{~s}^{-1}$ $\mathrm{Fe}^{2+}+\mathrm{H}_{2} \mathrm{O}_{2} \rightarrow \mathrm{Fe}^{3+}+\mathrm{OH}^{-}+\mathrm{OH}^{\bullet} \quad \mathrm{k}_{2}=60-80 \mathrm{M}^{-1} \mathrm{~s}^{-1}$ $\mathrm{RH}+\mathrm{H}_{2} \mathrm{O}_{2}\left(\mathrm{Fe}^{2+} / \mathrm{Fe}^{3+}\right) \longrightarrow[\mathrm{R}-\mathrm{OH}] \longrightarrow[\mathrm{R}-\mathrm{COOH}]$ Example: coumaric acid, tyrosol, p-hydroxobenzoic acid, phenolic compounds lead in dark reactions to oxalic and similar acids $\mathrm{pK}_{\mathrm{a}}(4-5)$ in line with the final $\mathrm{pH}$ of 4 observed in our case

Scheme 3.

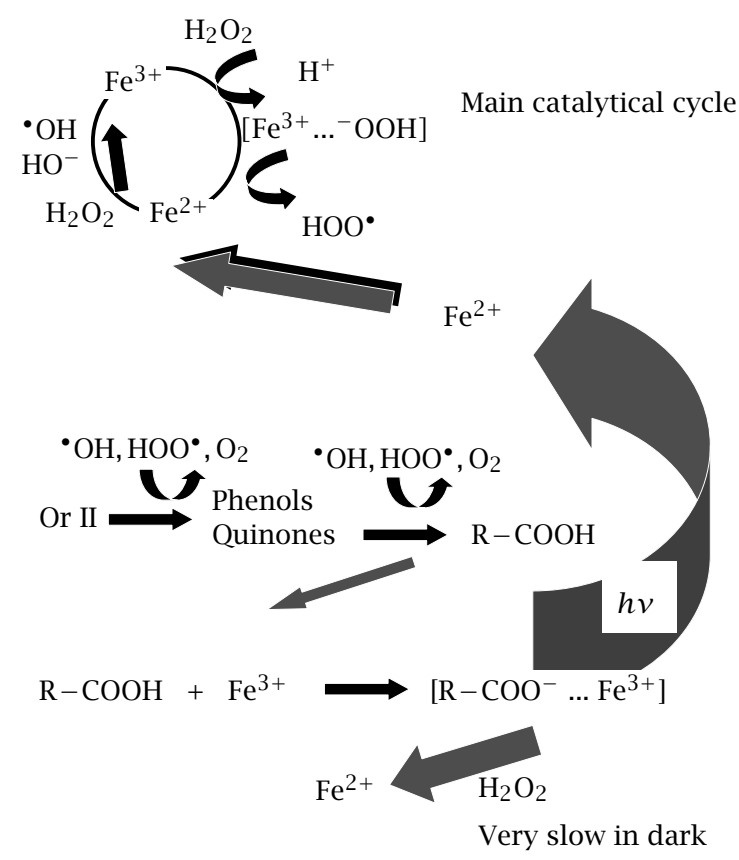

Scheme 4.

2.3. Modified block-copolymers thin films loaded with $\mathrm{Fe}^{3+}$ and $\mathrm{TiO}_{2}$. More recently [30], $\mathrm{Fe}^{3+}$, $\mathrm{Fe}_{2} \mathrm{O}_{3}$ and $\mathrm{TiO}_{2}$ have been immobilized on low cost polyethylene ${ }^{\circledR}$ modified copolymers films containing maleic anhydride anchoring groups. The observed rates of degradation of Orange II and halocarbons were only slightly below the rates observed during homogeneous Fenton photo-assisted degradation when $\mathrm{Fe}^{3+}$ was exchanged on the copolymer surface. Polyethylene is known to be the second most inert Dupont polymer after Teflon, a C $-\mathrm{F}$ polymer of widespread use. IR spectroscopy suggests that $\mathrm{Fe}^{3+} / \mathrm{Fe}_{2} \mathrm{O}_{3}$ interacts with the negatively charged conjugated carboxylic groups through $-\mathrm{COO}-\mathrm{Fe}^{3+}$. In the case of the copolymer$\mathrm{Fe}^{3+}$, the bands in the IR spectrum at 1523 and $\sim 1557 \mathrm{~cm}^{-1}$ correspond to two types of iron-carboxyl species. The strong attraction between the negative anhydride groups on the polymer surface and the $\mathrm{Fe}^{3+}$-ion leads to formation of metal to ligand transfer charge bond (MLTC) between the negatively anhydride group 
and the Fe-ion on the copolymer thin films. This accounts for the lack of $\mathrm{Fe}^{3+}$ ions leaching into the solution. It is also the reason for the attachment of a monolayer of complexed species on the thin film surface. During the last decade it has been repeatedly invoked that homogenous Fenton processes involve three reactive intermediate species:

a) the formation of oxidative radicals like $\mathrm{OH}^{\circ}, \mathrm{HO}_{2}{ }^{\circ}$ and other oxidative radicals due to the $\mathrm{H}_{2} \mathrm{O}_{2}$ added in solution,

b) the possible formation but controversial solution species Fe(IV) and finally

c) the formation of Fe-chelates as shown in Scheme 4 .

The importance of the $\left[\mathrm{R}-\mathrm{COO}^{-}\right]$as a preferred reaction pathway in the decomposition of pollutants on the surface [polyethylene- $\mathrm{COO}^{-}-\mathrm{Fe}^{3+}$ ] is rationalized by the observation that the copolymer thin films should be attacked by $\mathrm{OH}^{\circ}, \mathrm{HO}_{2}{ }^{\circ}$ and other oxidative radicals available in solution. But this was not the case for [polyethylene- $\mathrm{COO}^{-}-\mathrm{Fe}^{3+}$ ] even when used over long times (300 hours) and/or repeated recycling below the polyethylene flowing temperature $\left(80^{\circ} \mathrm{C}\right)$. Moreover, the observation reported recently [31] that degradation of organic compounds is able to take place during Fenton photo-assisted treatment in the presence of $3000 \mathrm{ppm}$ of $\mathrm{Cl}^{-}$-ion involving also the formation of $\mathrm{Cl}_{2}{ }^{-\circ}$ radicals lends further support to the existence of Fe-carboxylate complexes in solution during the mineralization of organic compounds to $\mathrm{CO}_{2}$.

\section{CONCLUSIONS}

The results presented in this study show that supported catalysts are a practical alternative to homogeneous systems or suspended catalytic devises in the field of pollution abatement. The supported catalyst should have three inherent characteristics to be viable: a) not leach out the catalytic metal-ion or semiconductor, b) not be corroded by the oxidative radicals generated in solution and c) intervene in the degradation of the pollutant(s) with an adequate kinetics. The last condition is the most difficult to meet during the treatment of real industrial wastewaters. Our research program is currently designed to improve the kinetics of this type of processes.

\section{ACKNOWLEDGMENT}

This work has been possible due to the financial support of KTI/CTI TOP NANO 21 (Bern, Switzerland) under Grant $N^{\circ} 5320.1$ TNS

\section{REFERENCES}

[1] Ch. Acc. Walling, Chem. Res. 6 (1975), 125.

[2] B. Rupert, R. Bauer, and G. Heisler, J. Photochem. Photobiol. A 73 (1993), 75.
[3] J. Bandara, C. Morrison, P. Pulgarin, and J. Kiwi, J. Photochem. Photobiol. A 99 (1996), 57.

[4] V. Nadtochenko and J. Kiwi, Faraday Trans. 93 (1997), 2373.

[5] J. Edwards and R. Curci, Catalytic Oxidation with $\mathrm{H}_{2} \mathrm{O}_{2}$ as Oxidant (G. Strukul, Ed.), Kluwer, Academic, 1982.

[6] M. Halmann, Photodegradation of Water Pollutants; CRC Press, Boca Raton, Fla, 1996.

[7] European Economic Community, EEC, List of Council Directives 76/4647, Brussels, Belgium, 1982.

[8] C. Morrison, J. Bandara, and J. Kiwi, J. Adv. Oxid. Technol. 1 (1996), 160.

[9] H. Roques, Chemical Water Treatment, VCH. Pub. Co., New York, 1996.

[10] J. Bard, Integrated Chemical Systems, John Wiley \& Sons, New Yor, 1994.

[11] R. Lawson, B. Kiang, and R. Martin, Chem. Mater. 5 (1993), 400.

[12] G. Meissner, R. Memming, and B. Kastening, Chem. Phys. Letts. 96 (1983), 34.

[13] I. Bellobono, A. Carrara, B. Barni, and A. Gazzotti, J. Photochem. Photobiol. A 84 (1994), 90.

[14] R. Pozzo, M. Baltanas, and A. Cassano, Catal. Today 39 (1997), 219.

[15] H. Miyoshi, S. Nippa, and H. Uchida, Bull. Chem. Soc. Jpn. 63 (1994), 3880.

[16] R. Parton, I. Vankelecom, M. Casselman, J. Uytterhoeven, and P. Jacobs, Nature 394 (1994), 541.

[17] F. J. Waller, Catal. Rev. Sci. Eng. 28 (1986), 1.

[18] C. Pulgarin and J. Kiwi, Langmuir 11 (1995), 519.

[19] A. Olah, S. Prakash, and J. Sommer, Superacids, Wiley Interscience, New York, 1985, Chapter 1.

[20] M. D. Stansbury, Adv. Inorg. Chem. 33 (1989), 69.

[21] A. Lopez and J. Kiwi, J. Eng. Ind. Chem. Res. 40 (2001), 1852.

[22] J. Fernandez, J. Bandara, A. Lopez, Ph. Buffat, and J. Kiwi, Langmuir 15 (1999), 185.

[23] M. Dhananjeyan, J. Kiwi, P. Albers, and O. Enea, Helv. Chim. Acta 84 (2001), 3433.

[24] A. Harmer, E. Farneth, and Q. Sun, J. Amer. Chem. Soc. 118 (1996), 7708.

[25] V. Nadtochenko and J. Kiwi, J. Chem. Soc. Faraday Trans. 93 (1997), 2373.

[26] J. Bandara and J. Kiwi, New J. Chem. 23 (1999), 717.

[27] F. Herrera, C. Pulgarin, V. Nadtochenko, and J. Kiwi, J. Appl. Catal. B 16 (1998), 141.

[28] D. Sawyer, A. Sobkowiak, and T. Matsushita, Acc. Chem. Res. 29 (1996), 409.

[29] D. Sawyer, Ch. Kang, A. Llobet, and Ch. Redman, J. Amer. Chem. Soc. 115 (1993), 5817.

[30] M. Dhananjeyan, E. Mielczarski, K. Thampi, Ph. Buffat, M. Bensimon, A. Kulik, J. Mielczarski, and J. Kiwi, J. Phys. Chem. B 105 (2001), 12046.

[31] J. Kiwi, A. Lopez, and V. Nadtochenko, Environ. Sci. Technol. 34 (2000), 2162. 


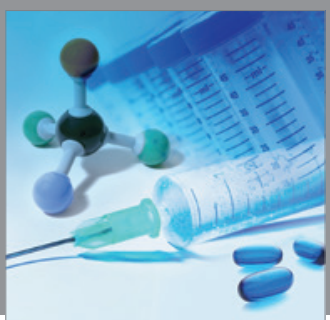

International Journal of

Medicinal Chemistry

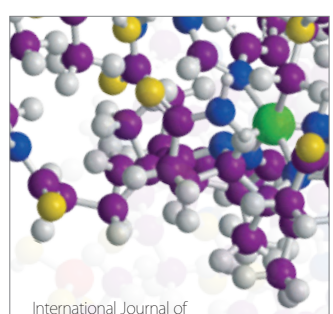

Carbohydrate Chemistry

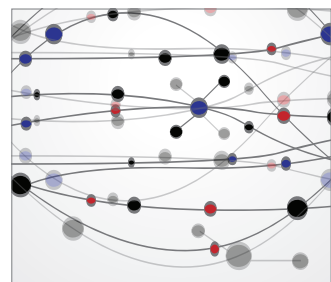

The Scientific World Journal
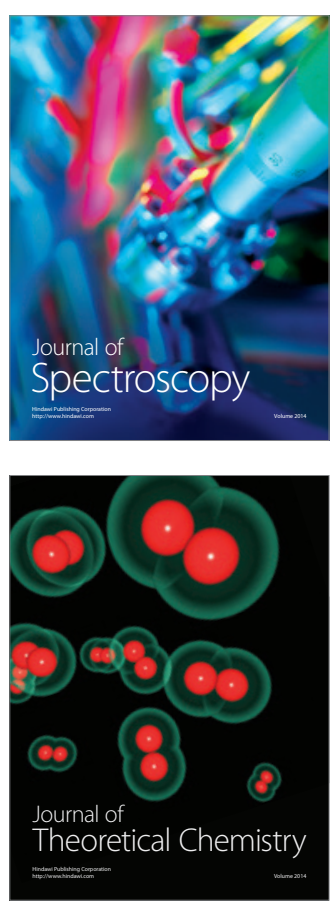
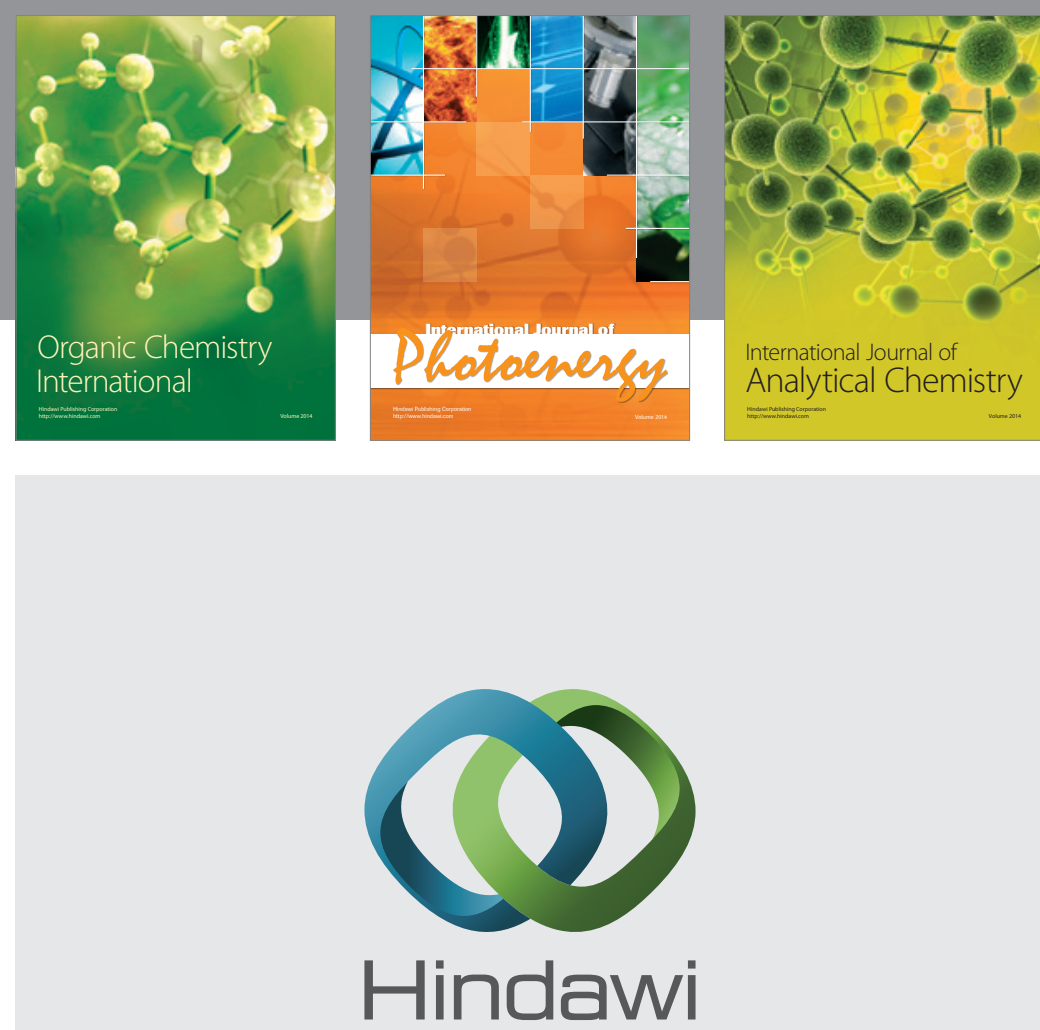

Submit your manuscripts at

http://www.hindawi.com
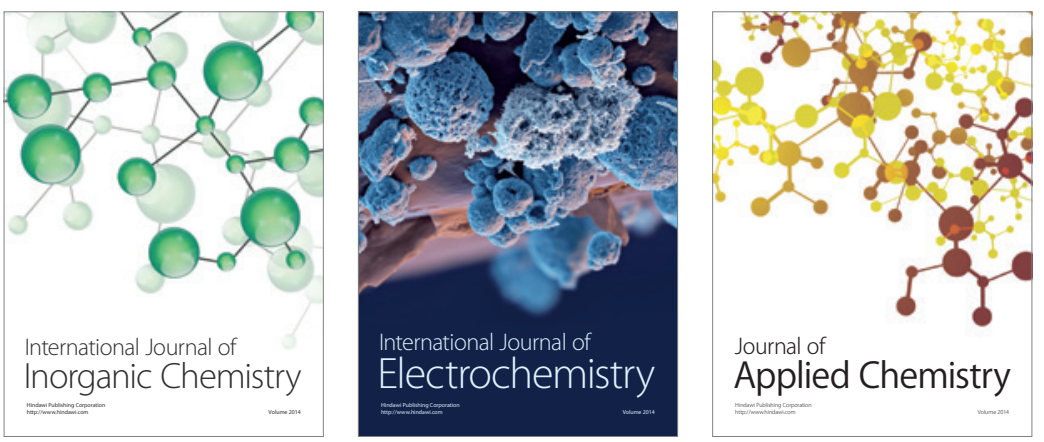

Journal of

Applied Chemistry
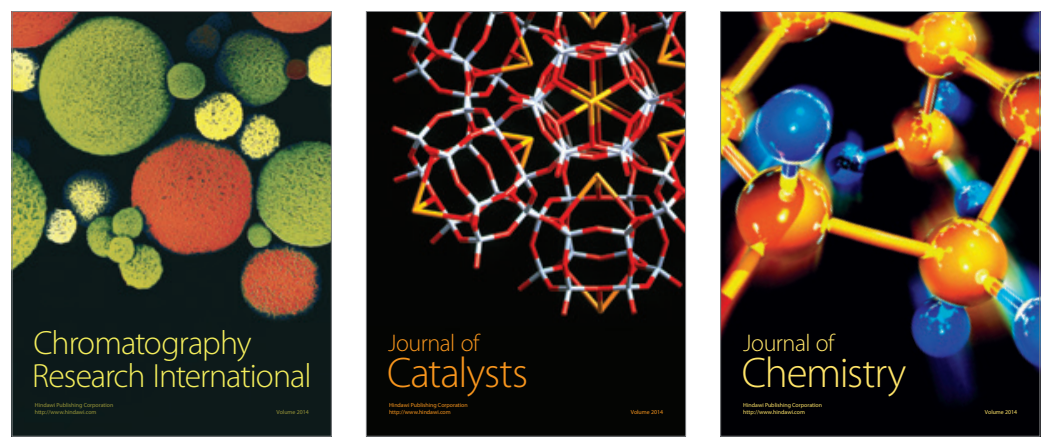
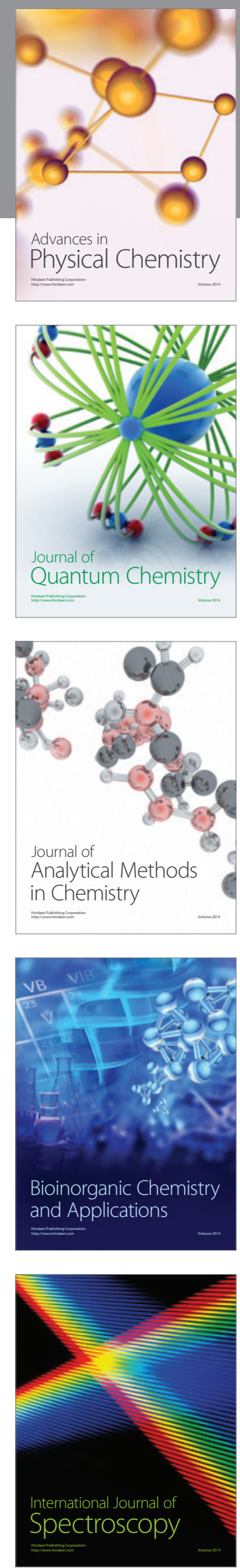